\title{
Histological and ultrastructural findings in a case of the Sézary syndrome
}

\author{
J. J. LABAzE, E. A. Moscovic, T. D. PhAM, AND H. A. AZAR
}

From the Department of Pathology, the Harlem Hospital Center, and Francis Delafield Hospital Divisions of $\vec{O}$ the College of Physicians and Surgeons, Columbia University, New York

SYNOPSIS This paper deals with the histological and ultrastructural findings in a case of the Sézary syndrome. The striking nuclear and cytoplasmic features of the Sézary cell are illustrated, and the similarities of this cell to the mycosis fungoides cell are once more stressed.

According to the original description (Sézary, 1949), Sézary's syndrome is characterized by generalized, intensely pruritic, oedematous and pigmented erythroderma, lymphadenopathy, 'monstrous histiomonocytes' in the circulating blood and, despite the patient's good general condition throughout most of the disease, an invariably fatal outcome in 18 to 40 months. Other, usually early, symptoms may include palmar and plantar hyperkeratosis with painful fissures, dystrophic nails, patchy pigmented involvement of mucous membranes, leonine facies, alopecia, and night sweats or chills, with normal or subfebrile body temperatures.

The histopathology of the skin lesions was also described in detail: irregular acanthosis with mixed hyperkeratosis and parakeratosis, intercellular epidermal oedema with foci of frank spongiosis as well as small cavities containing abnormal mononuclear cells, analogous to the Pautrier microabscesses of mycosis fungoides, and a dermal mononuclear cell infiltrate of variable intensity. In all tissues alike, including the peripheral blood, Sézary stressed the occurrence of a peculiar pleomorphic cell about which the most distinctive feature was a large, highly irregular, convoluted nucleus. He believed that it was a mesenchymal, more specifically, reticuloendothelial cell, and that it was unlike any previously described cell.

It was later suggested (Taswell and Winkelmann, 1961) that the presence of intracytoplasmic PASpositive granules was an added diagnostic feature of the Sézary cell. Not until recently has the cell type involved been found to have an equally characteristic ultrastructural appearance (Lutzner and Jordan, 1968) and to be quite similar to that of mycosis fungoides (Brownlee and Murad, 1970)

Received for publication 31 August 1971.

\section{Case Report}

A 61-year-old Negro male, by profession a linotypist, was admitted to Harlem Hospital Center $\vec{\theta}$ because of generalized macular erythroderma with $N$ intense itching for two years. His family history was non-contributory, but his past history revealed treatment for seborrhoea before the onset of the present symptoms and for an unspecified skin disease, presumably syphilitic, many years earlier. He also had a prostatectomy at the age of 51 .

On physical examination, he appeared in good general condition; his blood pressure was $160 / 80$ $\mathrm{mm} \mathrm{Hg}$, the pulse rate was 88 beats per minute, and he had a normal body temperature. The skin revealed generalized, pigmented, exfoliative dermatitis, puffiness of the face with leonine features, and scaly keratotic changes of the palms of the hands and soles of the feet. Markedly enlarged, rubbery, nontender axillary and inguinal nodes were palpable bilaterally. The spleen was not palpable, but the liver appeared to be somewhat enlarged.

Laboratory investigations gave the following results: haemoglobin level $13.8 \mathrm{~g} / 100 \mathrm{ml}$, haematocrit $\tilde{\sim}$ $40 \%$ and normal red cell morphology; a white cell $\sigma$ count of $34000 / \mathrm{c} \mathrm{mm}$ revealed a differential of $18 \%$ N neutrophils, $4 \%$ eosinophils, $5 \%$ monocytes, and $N_{\omega}$ $73 \%$ abnormal mononuclear cells most of which had the appearance of atypical lymphocytes; the 0 reticulocyte count was $2290 / \mathrm{c} \mathrm{mm}$, platelets $303000 / \mathrm{c} \mathrm{mm}$. Prothrombin times were within $\stackrel{\infty}{+}$ normal limits. A VDRL was non-reactive.

Total serum proteins were $7 \cdot 1 \mathrm{~g} / 100 \mathrm{ml}$ (albumins $3.94 \mathrm{~g} / 100 \mathrm{ml}$ and globulins $3 \cdot 16 \mathrm{~g} / 100 \mathrm{ml}$, a breakdown of individual globulin fractions showing $\alpha_{1}$ $0.28, \alpha_{2} 0.46, \beta 1.05$, and $\gamma 1.37 \mathrm{~g} / 100 \mathrm{ml}$ ). With the exception of an elevated uric acid level of $11.8 \mathrm{mg} /$ 
$100 \mathrm{ml}$, all other tests, including plasma urea, glucose, creatinine, serum electrolytes, acid and alkaline phosphatase, LDH, SGOT, etc, were within normal limits.

Haematological studies revealed that most of the abnormal white cells in the peripheral blood were small, averaging 6 to $8 \mu$ in diameter, but that

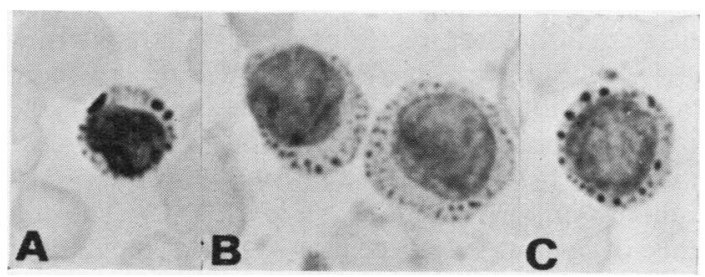

Fig. 1 Four Sézary cells from peripheral blood of this patient, with $P A S$-positive granules that vary in number, size, and intensity of staining (periodic acid Schiff. $A \times$ 150; $B$ and $C \times 100$ ). occasional cells reached up to $15 \mu$ in diameter, particularly in areas where films were spread thin. About $20 \%$ of those cells contained intensely PASpositive, diastase-sensitive, intracytoplasmic granules (Fig. 1); a few also contained isolated diastaseresistant granules. Regardless of the presence of granules, marked nuclear irregularities, such as protrusions, grooving, or folding, were observed in nearly every cell of that type; even when under low magnification such cells appeared to have the round, compact nuclei of lymphocytes. Such cells were not identified in marrow aspirates, which were concluded to be normocellular.

Attempts at obtaining the karyotype of the abnormal cells were unsuccessful in view of their inadequate response to phytohaemagglutinin stimulation. Crossen, Mellor, Finlay, Ravich, Vincent, and Gunz (1971) succeeded, however, in demonstrating that the predominant cell line in the Sézary syndrome has a mode of 76 chromosomes.

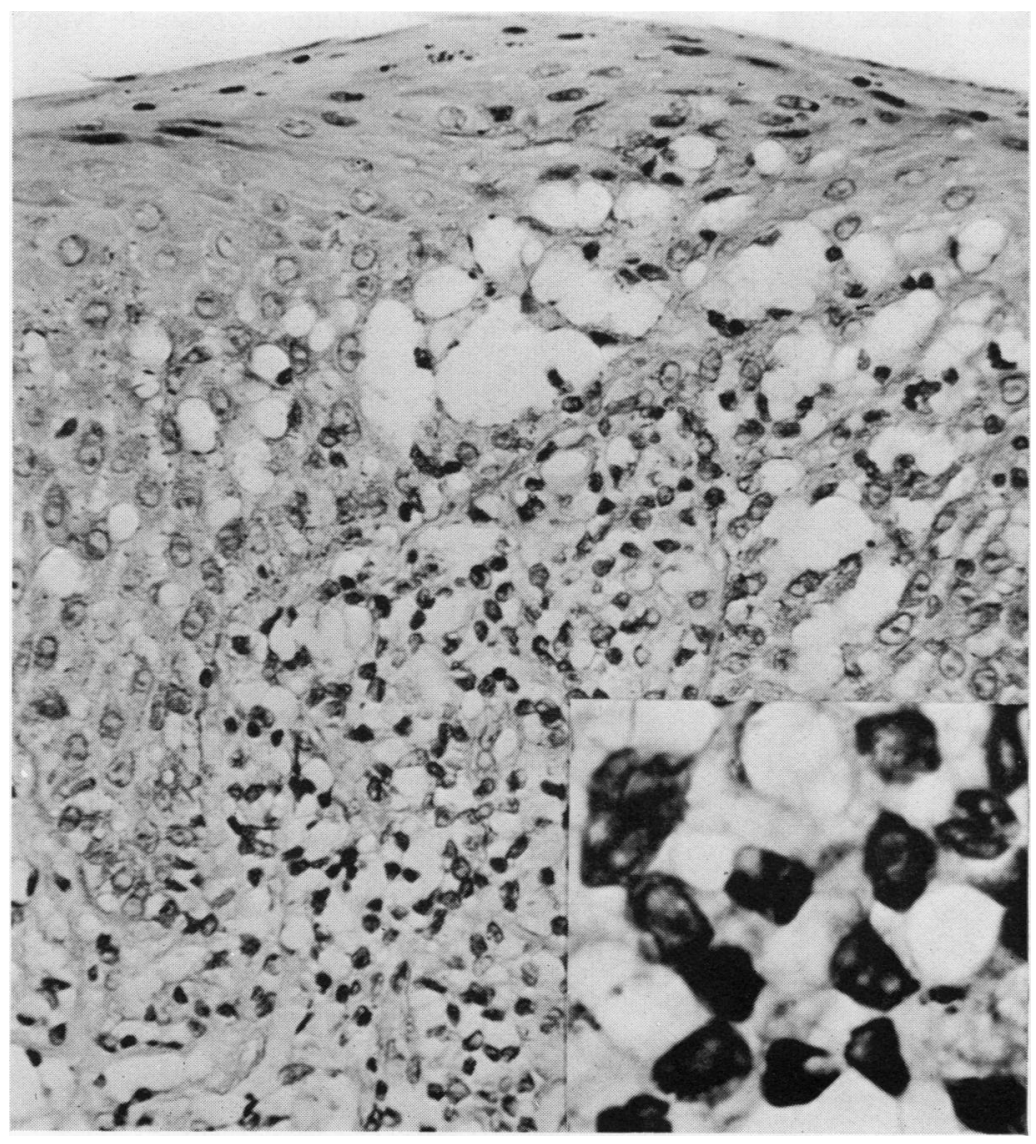

Fig. 2 Skin revealing parakeratosis, an area of marked spongiosis in suprabasal and Malpighian layer and a dermal infiltrate with vascular ectasia. Inset: high-power nuclear pleomorphism in dermal infiltrate (PAS, $\times 340$; inset, $\times 1280)$. 


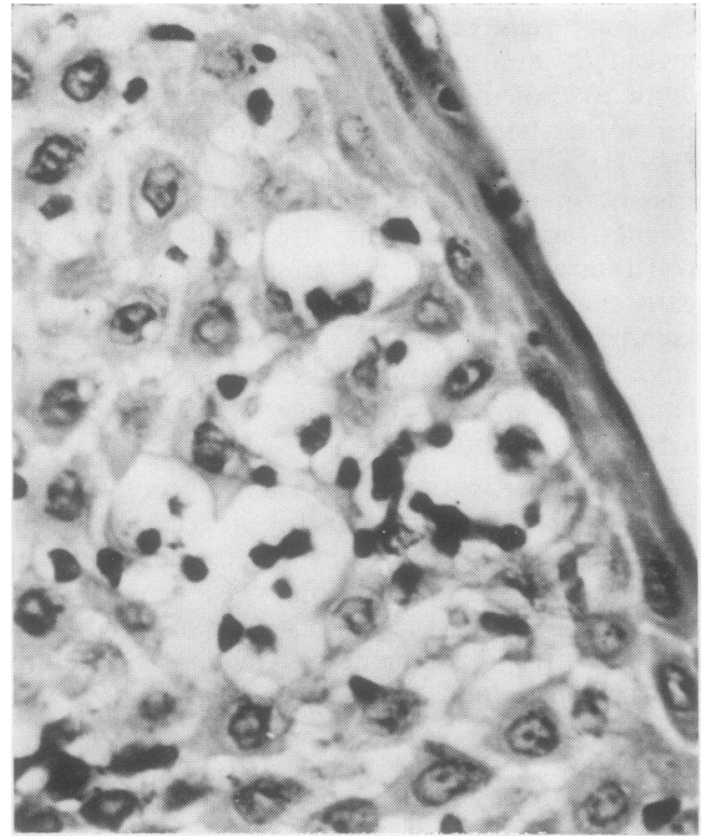

Fig. 3.

\section{Histopathological Findings}

The epidermis showed segmental acanthosis with variable parakeratosis and downgrowth of rete ridges, widely scattered foci of spongiosis in the Malpighian layer (Fig. 2), and a few Pautrier-like microabscesses in the basal and malpighian layer, containing loose aggregates of atypical mononuclear cells, often surrounded by a clear halo (Fig. 3). Such cells were also noted migrating through the epidermis $\overrightarrow{0}$ singly, revealing a considerable degree of ameaboid plasticity within narrow intercellular spaces. In the upper half of the dermis they formed a fairly dense infiltrate which under low power appeared misleadingly uniform, lymphocytoid (Fig. 2). The full ơ range of nuclear variations was apparent only under oil immersion. Mitotic figures were not recognized among those cells, and PAS-positive granules were found in them exceptionally. Apart from that, there was oedema, vascular ectasia, and a variable number of melanophages as well as free melanin pigment in the uppermost dermis, denoting pigmentary incontinence of the involved epidermal segments.

The histological architecture of small lymph $N$

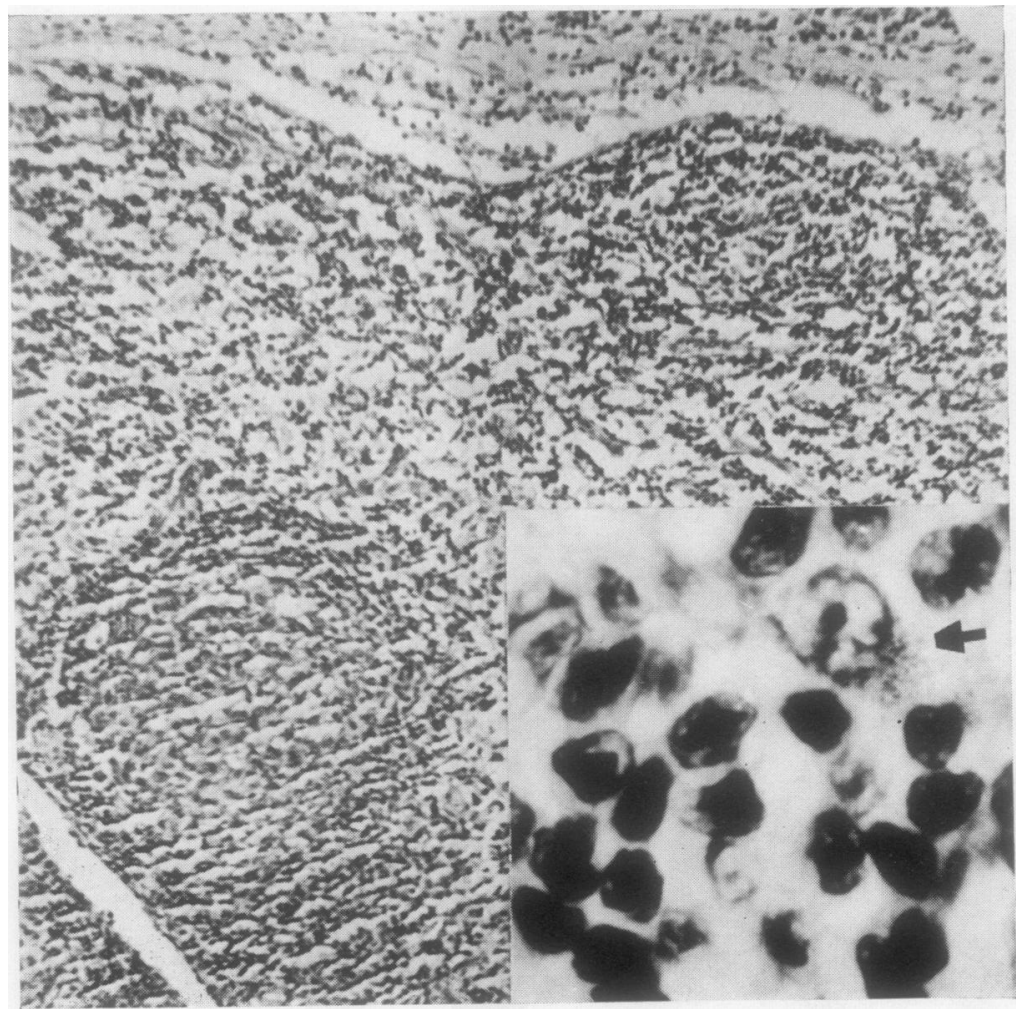

Fig. 4.
Fig. 3 Pautrier-like microabscesses in epidermis, containing atypical mononuclear cells surrounded by clear halo. Migration of a few single cells in interstitial spaces $(H \& E \times 520)$. Fig. 4 Histological
appearance of enlarged axillary lymph node, revealing capsular N infiltrate, monotonous cellularity, and a single relatively preserved follicular structure ( $H$ and $E \times 520)$. Inset High-power showing $P A S$-positive large reticulum cell $\left(P A S \times 1 \frac{1}{2} 280\right)$. 

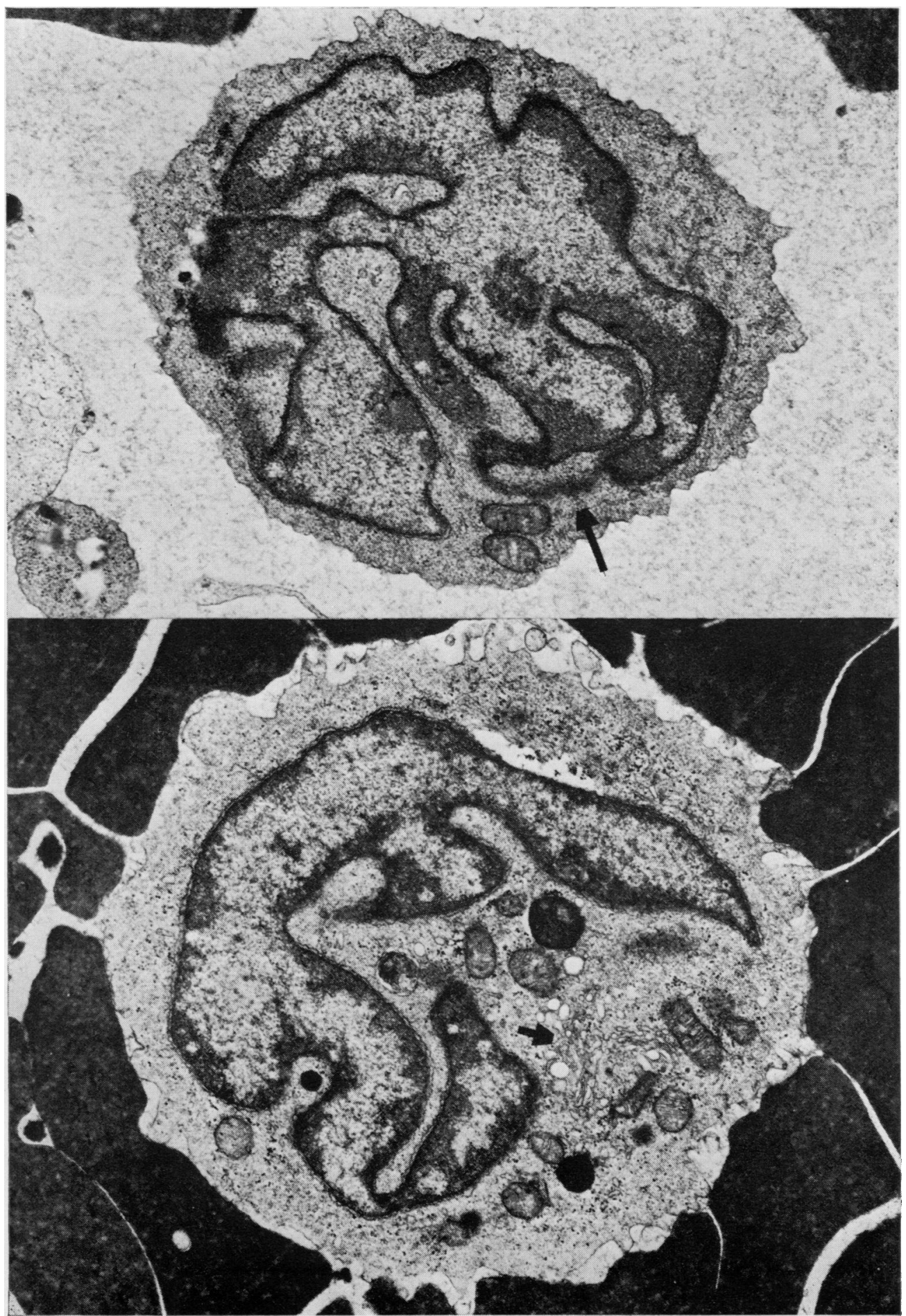

Fig. 5 Sézary

cell with

convoluted

nuclear pro-

jections, directed

toward one side

of the cell. Single

nucleolus and

margination of

nuclear

chromatin. Thin,

wavy bridge

between the ends

of two nuclear

fronds (arrow)

consists of

nuclear

membrane

$(\times 13500)$.

Fig. 6 Sézary cell with

mitochondria

surrounding

Golgi apparatus

(arrow) located in cup-like hollow

between nuclear

projections

$(\times 13500)$. 


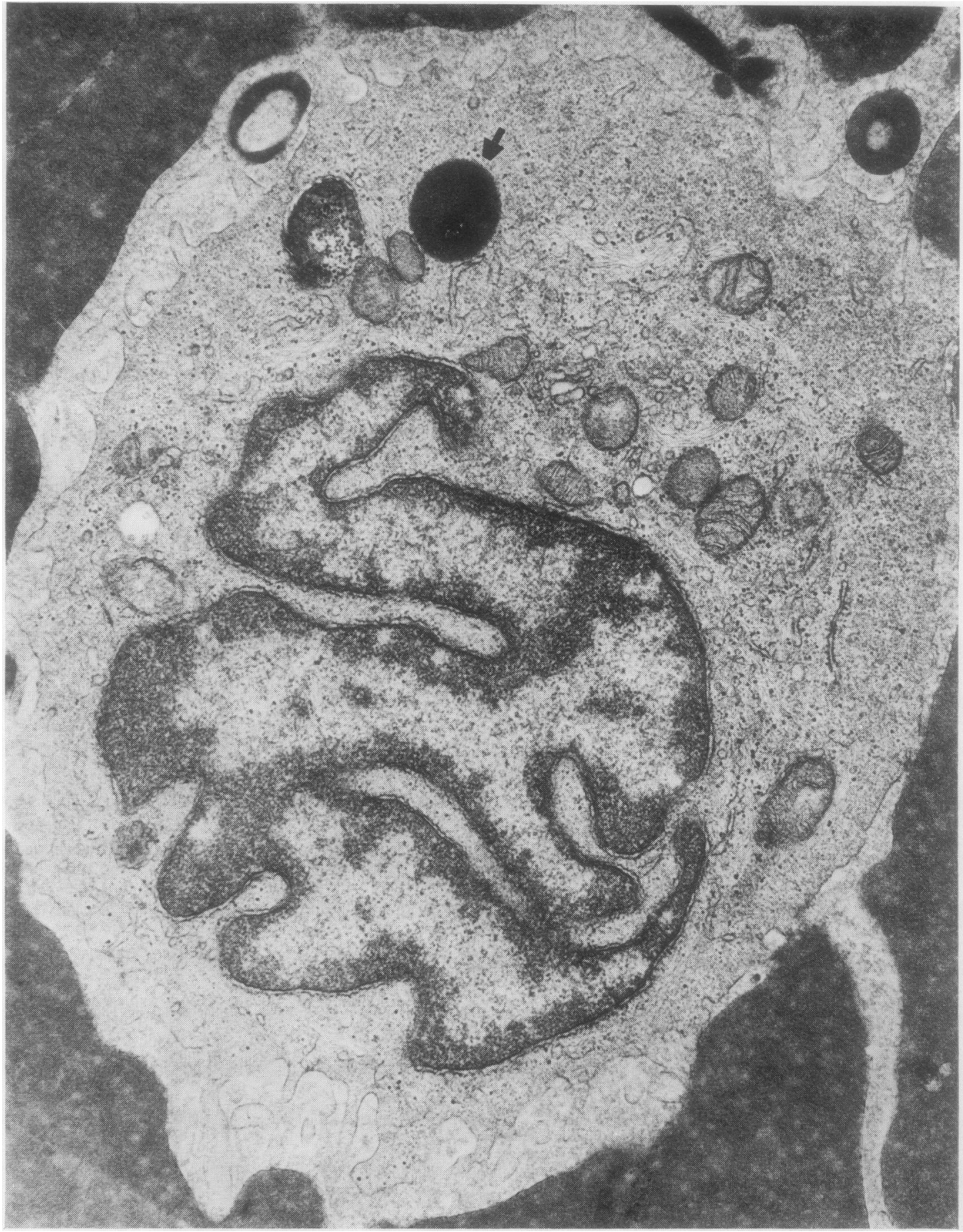

Fig. 7 Cerebriform nucleus is located on one side of cell, the opposite side containing numerous mitochondria and an oval dense body (arrow), with several rounded areas of greater density. Two similar bodies lying outside the cell reveal oval areas of electron translucency. Scattered areas of fine fibrillary appearance are seen in the cytoplasm, as well as what appears to be single granules of glycogen $(\times 28800)$. 


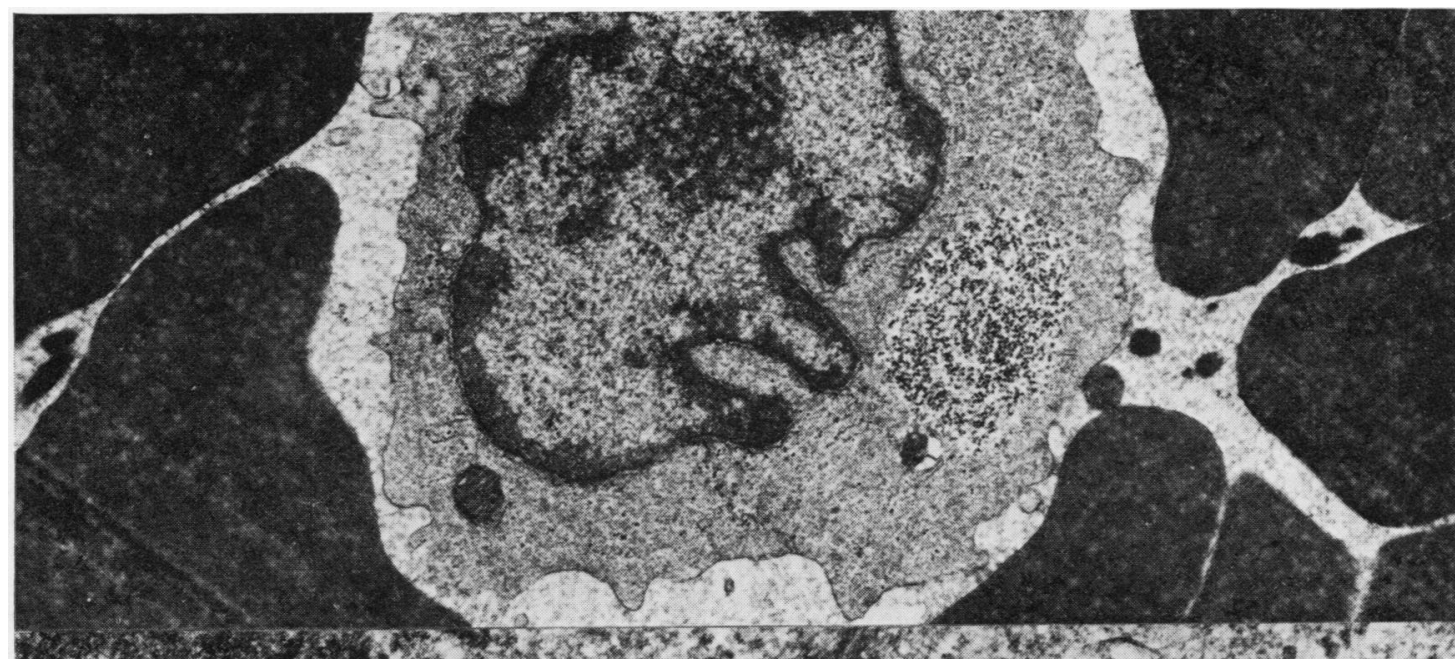

Fig. 8.

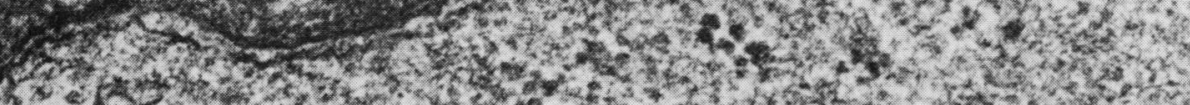

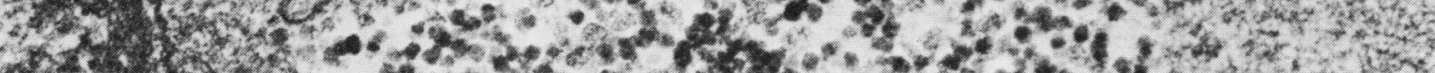

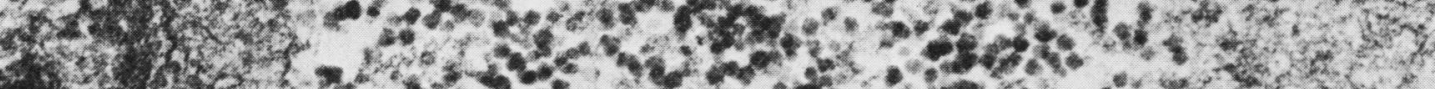

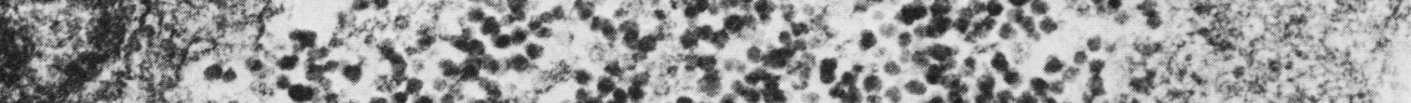

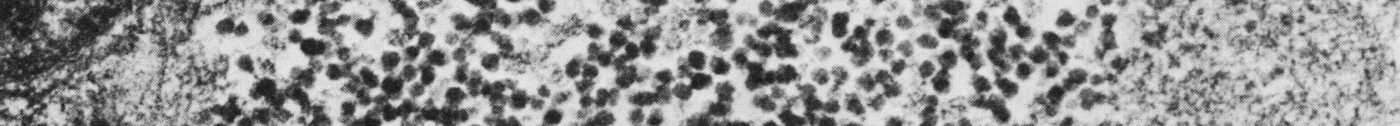

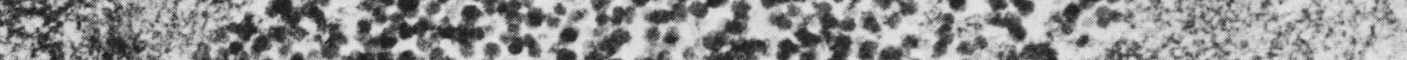

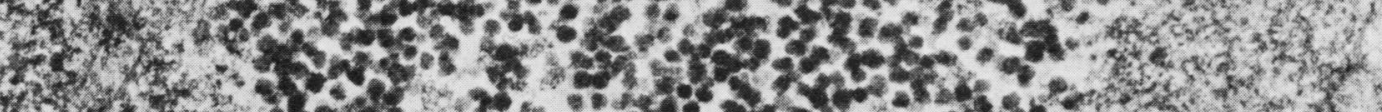

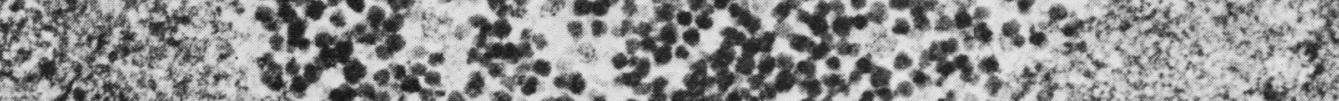

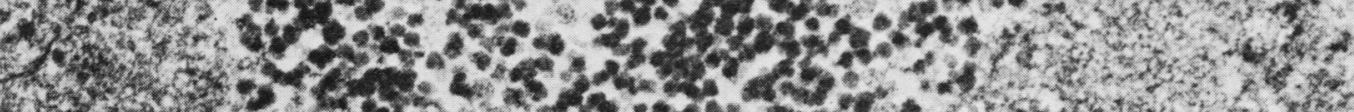

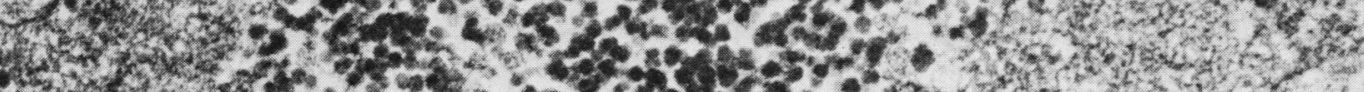

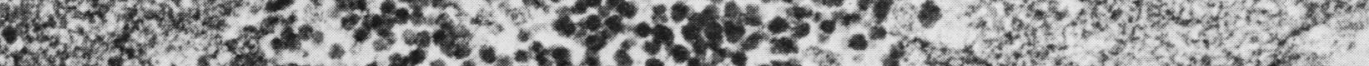

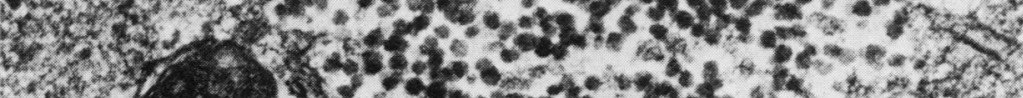

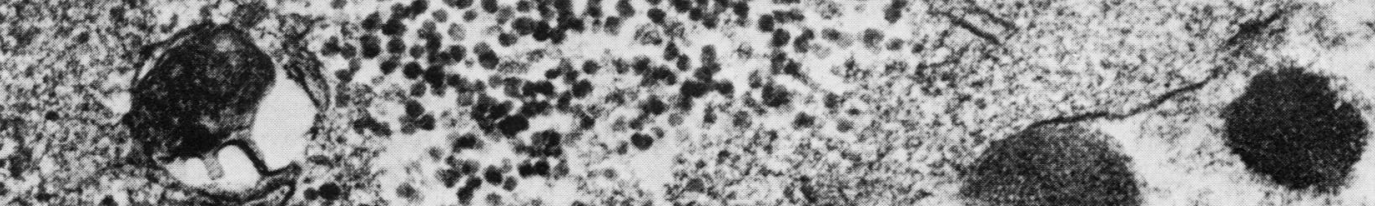

Fig. 9. A.
Fig. 8 Sézary cell with typical clustering of glycogen granules in right central area. Such an area corresponds to a large diastase-sensitive PAS-positive granule such as seen in Fig. 1 A and $1 C(\times 11250)$

Fig. 9 Detail of cluster of glycogen granules shown in Figure 8. Note the crowding of uniform beta glycogen particles with absence of limiting membrane $(\times 50000)$. 
nodes was relatively undisturbed, whereas the largest node $(4 \mathrm{~cm})$ of the axillary specimen revealed merely a few remaining follicular structures (Fig. 4). Instead there was a monotonous combination pattern of what appeared to be histiocytic cells, with abundant pale cytoplasm, and interspersed small clusters of lymphocytoid cells. Such fields suggested a reactive hyperplastic process rather than neoplasia though they bore a slight resemblance to the 'starry sky' pattern of Burkitt's lymphoma. Under high power, both types of cell displayed the nuclear pleomorphism of Sézary cells, and exhibited occasional mitotic activity. PAS-positive granules were exceedingly rare in either cell type. However, PASpositive material was present in isolated large reticulum cells. These nuclear features appeared to be normal (Fig. 4, inset). In routine haematoxylin and eosin stains that material correlated well with a brown lipofuscin-like pigment which was ironnegative and partly acid-fast. The capsule was not thickened in any of the lymph nodes examined but showed mild focal infiltration by abnormal mononuclear cells. In addition, sinusoidal outlines were blurred and there was vascular proliferation with marked endothelial hyperplasia even in small lymph nodes.

\section{Electron Microscopic Studies}

MATERIALS AND METHODS

Buffy coat pellets were fixed for three hours in $3 \%$ phosphate-buffered glutaraldehyde, $p \mathrm{H} 7 \cdot 4$, and postfixed in $1 \%$ phosphate-buffered osmium tetroxide, $p \mathrm{H} \mathrm{7.4}$. The cell suspension was then dehydrated gradually in acetone and embedded in araldite.

Thin sections were made with the aid of an LKB ultratome III and mounted on formvar-coated mesh grids. The sections were stained in $2 \%$ alcoholic uranyl acetate and in Reynold's lead citrate for five minutes each, and then viewed with the aid of an Hitachi HU-LLE electron microscope at $75 \mathrm{kv}$.

\section{ULTRASTRUCTURAL FINDINGS}

The predominant cell type among the white cell population distinctly differed from any other cell normally occurring in the peripheral blood. It was easily identifiable by its convoluted cerebriform nucleus, with the chromatin condensed at the nuclear membrane and a prominent, apparently single, nucleolus. It also had a relatively translucent, light-textured cytoplasm with scanty smoothsurfaced endoplasmic reticulum, a variable number of mitochondria, in some planes of section a Golgi apparatus, and occasional aggregates of glycogen as well as isolated oval membrane-bounded, electron- dense bodies (Figs. 5, 6, 7, 8, and 9). In fact, these cells conformed in almost every respect with the previously described ultrastructural characteristics of both Sézary cells (Lutzner and Jordan, 1968) and mycosis fungoides cells (Brownlee and Murad, 1970).

\section{Discussion}

Undoubtedly, one of the most puzzling aspects of the Sézary syndrome concerns the nature and origin of the peculiar cells present in the skin lesions, lymph nodes and peripheral blood. The purpose of the present electron microscopic study was twofold: to see if the fine structure of the Sézary cell was indeed as distinctive as reported previously, and to enquire whether the presence of such cells in the peripheral blood might not in some way be related to possible changes in lymphocytes. This is in view of the fact that Sézary cells and lymphocytes could often not be distinguished from each other by simple light microscopy.

As to the fine structural features of Sézary cells, these are undoubtedly distinctive. It remains to be shown whether similar cells will be found in the normal state or in conditions other than Sézary's syndrome and mycosis fungoides. The present study further revealed that Sézary cells contained both diastase-sensitive and diastase-resistant PAS-positive granules, the vast majority of the former variety. The rich glycogen content of the cells has also been borne out by our electron micrographs. The presence of glycogen may not be a reliable criterion for ruling out a cell of the lymphocytic series (Mitus, Bergna, Mednikoff, and Dameshek, 1958). As for diastaseresistant granules, these probably correspond to the oval membrane-bounded dense bodies seen under the electron microscope.

The present study showed that, while ultrastructurally typical lymphocytes were difficult to find, they were not altogether absent from the peripheral blood in this case. Nevertheless, their numbers were so significantly reduced that some relation to Sézary cells seems possible, either because the involved cells are somehow derived from lymphocytes or represent altered or transformed lymphocytes. In the same manner as phytohaemagglutinin and other mitogens may bring out a series of structural changes in lymphocytes (Naspitz and Richter, 1968), the possibility that Sézary cells represent transformed lymphocytes is suggested by our failure to elicit in the former cells a response to phytohaemagglutinin. It must be pointed out, however, that Crossen et al (1971) observed in one patient with Sézary's syndrome a marked response of her leucocytes to phytohaemagglutinin in vitro. Treatment of this patient's leucocytes with other mitogens produced a poor 
response. In mixed leucocyte cultures the patient's cells reacted very poorly, but were able to stimulate transformation of donor lymphocytes.

That Sézary cells may be derived from lymphocytes is in keeping with previously expressed opinions postulating that Sézary's syndrome is no more than a clinical variant of leukaemic reticuloendotheliosis (Tedeschi and Lansinger, 1965). Already Sézary himself had suggested that his 'new type' of cell was a reticuloendothelial cell. Despite the absence, to our knowledge, of any ultrastructural evidence that the cell type involved in leukaemic reticuloendotheliosis is similar to or identical with that of Sézary's syndrome, there are considerable clinical grounds for accepting such a possibility. According to Gosselin, Hanlon, and Pease (1956), the skin is involved in $28 \%$ and the lymph nodes in $45 \%$ of cases with leukaemic reticuloendotheliosis. Besides, the average survival time of 3.5 years is similar to that in Sézary's syndrome. In addition, the cell type described in the peripheral blood (Bouroncle, Wiseman, and Doan, 1958) may be inferred to be morphologically similar to the Sézary cell, even though the distinctive PASpositive granules have not been investigated in the former.

The conclusion we draw from the present study is that the cell type involved, although of uncertain origin, has certain distinctive ultrastructural features, and is similar to the cell type described in mycosis fungoides, suggesting that the two conditions are morphologically related. A possible relationship of the two to leukaemic reticuloendotheliosis awaits confirmation.

\section{References}

Bouroncle, B. A., Wiseman, B. K., and Doan, C. A. (1958). Leukemic reticuloendotheliosis. Blood, 13, 609-630.

Brownlee, T. R., and Murad, T. M. (1970). Ultrastructure of mycosis fungoides. Cancer (Philad.), 26, 686-698.

Crossen, P. E., Mellor, J. E. L., Finley, A. G., Ravich, R. B. M., Vincent, P. C., and Gunz, F. W. (1971). The Sézary syndrome. Cytogenetic studies and identification of the Sezary cell as an abnormal lymphocyte. Amer. J. Med., 50, 24-34.

Gosselin, G. R., Hanlon, D. G., and Pease, G. L. (1956). Leukaemic reticuloendotheliosis. Canad med. Ass., J., 74, 886-891.

Lutzner, M. A., and Jordan, H. W. (1968). The ultrastructure of an abnormal cell in Sézary's syndrome. Blood, 31, 719-726.

Mitus, W. J., Bergna, L. J., Mednicoff, I. B., and Dameshek, W. (1958). Cytochemical studies of glycogen content of lymphocytes in lymphocytic proliferations. Blood, 13, 748-756.

Naspitz, C. K., and Richter, M. (1968). The action of phytohemagglutinin in vivo and in vitro, a review. Progr. Allergy, 12, 1-85.

Sézary, A. (1949). Une nouvelle réticulose cutanée. La réticulose maligne leucémique à histio-monocytes monstrueux et à forme d'érythrodermie oedémateuse et pigmentée. Ann. Derm. Syph., 9,5-22.

Taswell, H. F., and Winkelmann, R. K. (1961). Sézary syndrome: a malignant reticulemic erythroderma. J. Amer. med. Ass., 177, 465-472.

Tedeschi, L. G., and Lansinger, D. T. (1965). Sézary syndrome: a malignant leukemic reticuloendotheliosis. Arch. Derm., 92, 257-262. 